\title{
Analysis of Arithmetic and Huffman Compression Techniques by Using DWT-DCT
}

\author{
Gaurav Kumar \\ Block IT Assistant, Government of Bihar, India \\ Email: gaurav.hardworker@gmail.com \\ Rajeev Kumar \\ Department of Computer Science, Central University of South Bihar, Gaya, India \\ Email: rajeev6136@gmail.com
}

Received: 03 January 2021; Accepted: 01 March 2021; Published: 08 August 2021

\begin{abstract}
In the recent era, digital contents are exchanging over the internet and it has increased exponentially. Sometimes, we need small sizes to share the real world, because of narrow bandwidth. Hence, the data compression concept came in limelight to utilize the storage capacity and available bandwidth efficiently. This paper presents an analysis of Arithmetic and Huffman compression techniques based on a hybrid combination of the DWT-DCT techniques. The input image is decomposed up to the $3^{\text {rd }}$ level by using the DWT and then Arithmetic \& Huffman coding is applied separately on quantized sub-bands on $2^{\text {nd }}$ as well as $3^{\text {rd }}$ level coefficients from approximation subbands to get a high compression ratio and high peak signal-to-noise ratio values. On the third level approximation subband, the DCT method is applied to reduce the blocking effect. Simulation results show that the Arithmetic coding exhibits higher CR than Huffman coding, but smaller PSNR values.
\end{abstract}

Index Terms: Discrete Wavelet Transform; Discrete Cosine Transform; Arithmetic Coding; Huffman Coding; PSNR; MSE; CR.

\section{Introduction}

Due to the rapid growth of the Internet and the advancements in digital camera technology in recent times, it creates a big challenge for storage requirements of images. Such images need more disk space to store them and higher bandwidth to transmit them over the Internet. Due to this reason, we need different compression techniques for image compression that can be used to save our disk space and bandwidth. The compression method compresses the image as much as possible so that the size gets reduced. Compression and decompression methods are very useful to compress our multimedia contents in a very effective way and also it is in a reversible form so that the signal can be reconstructed without loss of value.

Generally, lossless and lossy compression methods are used to compress our media contents [1]. The lossless compression scheme is useful to removed redundant information from input signals. That's why the original signal can be easily recovered completely. In this technique, the compression ratio (CR) is low, but recovered information has no loss. The lossless compression method is one of the best approaches in the compression area. The lossy compression technique has higher compression values but there are some losses of data during decompression. It means that the media content is not exactly achieved after decompression [2].

There are various techniques for image compression in the literature based on Discrete Wavelet Transform (DWT) [3-6], Vector Quantization (VQ) [17-19], and Discrete Cosine Transform (DCT) [6-9]. VQ is a lossy technique whereas the other two are lossless. This paper presents an analysis of Arithmetic [10-13] and Huffman [14-16] based variablelength coding for compression.

The rest of this paper is organized as follows: Section 2 presents the summarization of related works. Section3 presents the methodology of the compression scheme and performance matrices. Simulation results and analysis are given in section 4. Finally, section 5 sums up the conclusions and future work.

\section{Literature Review}

In this section, we summarized the compression related work which has attracted by many researchers in recent time are as below: 
Chen [20] has proposed a novel bit-rate-reduced approach for reducing the memory required to store a remote diagnosis and rapid transmission. They adopted an $8 \times 8$ DCT approach to perform the sub-band decomposition. The technique performs well in high-speed image coding and transmission using the DCT-CSPIHT technique. It provides less computational complexity using wavelet decomposition and the quality of the decompressed image has improved.

Corinthios et al. [5] proposed an improved hybrid technique (DWT-DCT) for compression. In this technique, two thresholds are taken to improve the compression. In terms of PSNR, the hybrid technique outperforms the DCT based technique. This technique also gives better results (in terms of PSNR) in comparison to DWT-improved but only in the case when the transform coefficients are below 20 percent.

Starosolski [21] presented simple color space transformations for lossless image compression and a couple of their variants. The three sets of test images and significantly different compression algorithms are: predictive JPEG-LS, DWT-based JPEG2000, and DCT-based JPEG X. RDgDb and A2 have a disadvantage in terms of the expansion of one bit, in the dynamic range of chroma component.

Kumar et al. [27] have proposed DWT based scheme for embedding the watermark after the compression of speech signals. Kumar et al. [28] have proposed speech watermarking techniques based on the LSB method. In this paper, they used the compression method for embedding the watermark.

Kumar et al. [29] proposed video watermarking techniques based on the DWT method for finding the quality of signals. They used the quantization process for compressed his file. Kumar et al. [30] proposed a technique for image compression based on DWT-DCT using arithmetic and Huffman coding with low complexity. Simulation results show that the technique has a better compression ratio than conventional arithmetic encoders.

After reviewing the literature, we have concluded that the Arithmetic and Huffman coding along with transformation techniques are frequently used in lossless image compression schemes; therefore it is imperative to test which compression coding gives optimum results. This paper presents the analysis of Arithmetic and Huffman compression techniques using DWT and DCT.

\section{Methodology}

Two-color images (Lena and Baboon) fewer than two different extensions (.jpeg and .bmp) are taken for the analysis of the compression technique. After compressing these two images the decompression is performed to analyze the performance of the technique in terms of evaluation parameters (PSNR and CR). The various steps of the technique (compression and decompression) as given in Fig.1.

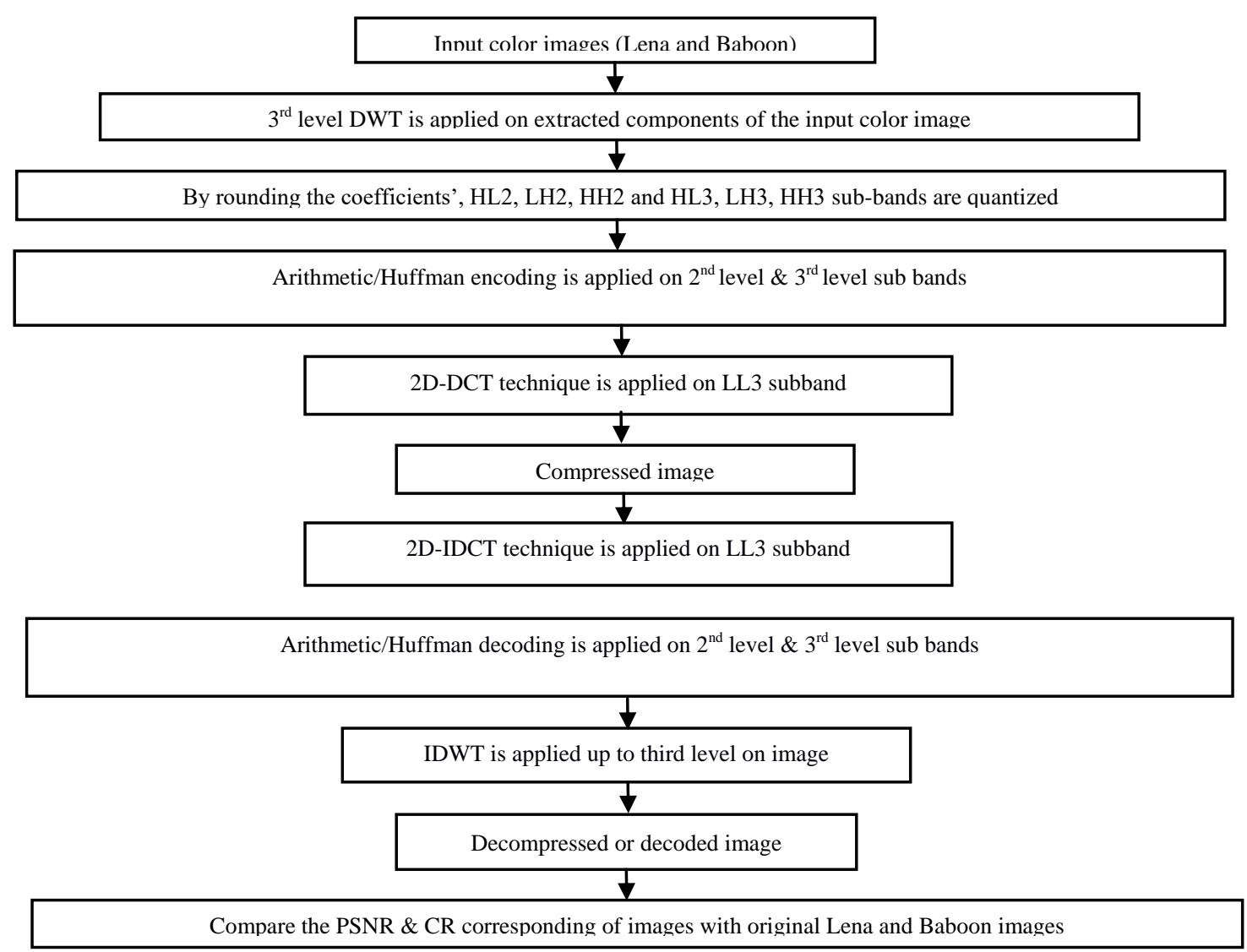

Fig. 1. Flow diagram of the compression and decompression schemes. 
Various steps to implement the compression, are as given below

Step 1. Input a color image (size 512*512).

Step 2. Red, Green, and Blue components are extracted from the colored images, and DWT is applied up to the third level.

For First level DWT:

$\left[\mathrm{C}_{\mathrm{A}}, \mathrm{C}_{\mathrm{H}}, \mathrm{C}_{\mathrm{V}}, \mathrm{C}_{\mathrm{D}}\right]=\mathrm{DWT}\left(\mathrm{Components,} \mathrm{'filter \_ name');}\right.$

For Second level DWT:

For third-level DWT:

$\left[\mathrm{C}_{\mathrm{A} 1}, \mathrm{C}_{\mathrm{H} 1}, \mathrm{C}_{\mathrm{V} 1}, \mathrm{C}_{\mathrm{D} 1}\right]=\mathrm{DWT}\left(\mathrm{C}_{\mathrm{A}}\right.$, 'filter_name' $)$;

$\left[\mathrm{C}_{\mathrm{A} 2}, \mathrm{C}_{\mathrm{H} 2}, \mathrm{C}_{\mathrm{V} 2}, \mathrm{C}_{\mathrm{D} 2}\right]=\mathrm{DWT}\left(\mathrm{C}_{\mathrm{A} 1}\right.$, 'filter_name');

Step 3. Quantization operation is performed on sub-bands of $2^{\text {nd }}$ level $\left(\mathrm{C}_{\mathrm{A} 1}, \mathrm{C}_{\mathrm{H} 1}, \mathrm{C}_{\mathrm{V} 1}, \mathrm{C}_{\mathrm{D} 1}\right) \& 3^{\mathrm{rd}}$ level $\left(\mathrm{C}_{\mathrm{A} 2}, \mathrm{C}_{\mathrm{H} 2}\right.$, $\mathrm{C}_{\mathrm{V} 2}, \mathrm{C}_{\mathrm{D} 2}$ ).

$$
\begin{aligned}
& \text { For } 2^{\text {nd }} \text { level }\left(\mathrm{C}_{\mathrm{A} 1}, \mathrm{C}_{\mathrm{H} 1}, \mathrm{C}_{\mathrm{V} 1}, \mathrm{C}_{\mathrm{D} 1}\right) \text { : } \\
& \qquad\left[\mathrm{C}_{\mathrm{H} 1 \mathrm{q}}, \mathrm{C}_{\mathrm{V} 1 \mathrm{q}}, \mathrm{C}_{\mathrm{D} 1 \mathrm{q}}\right]=\operatorname{round}\left(\mathrm{C}_{\mathrm{H} 1}, \mathrm{C}_{\mathrm{V} 1}, \mathrm{C}_{\mathrm{D} 1}\right) \text {; }
\end{aligned}
$$

For $3^{\text {rd }}$ level3 $\left(\mathrm{C}_{\mathrm{A} 2}, \mathrm{C}_{\mathrm{H} 2}, \mathrm{C}_{\mathrm{V} 2}, \mathrm{C}_{\mathrm{D} 2}\right)$ :

$\left[\mathrm{C}_{\mathrm{H} 2 \mathrm{q}}, \mathrm{C}_{\mathrm{V} 2 \mathrm{q}}, \mathrm{C}_{\mathrm{D} 2 \mathrm{q}}\right]=\operatorname{round}\left(\mathrm{C}_{\mathrm{H} 2}, \mathrm{C}_{\mathrm{V} 2}, \mathrm{C}_{\mathrm{D} 2}\right)$;

Step 4. Arithmetic \& Huffman coding is applied on sub-bands of $2^{\text {nd }}$ level $\left(\mathrm{C}_{\mathrm{A} 1}, \mathrm{C}_{\mathrm{H} 1}, \mathrm{C}_{\mathrm{V} 1}\right.$, and $\left.\mathrm{C}_{\mathrm{D} 1}\right) \& 3^{\text {rd }}$ level $\left(\mathrm{C}_{\mathrm{A} 2}\right.$, $\mathrm{C}_{\mathrm{H} 2}, \mathrm{C}_{\mathrm{V} 2}$, and $\mathrm{C}_{\mathrm{D} 2}$ ) separately.

For Arithmetic encoding:

For Huffman encoding:

$$
\mathrm{R} 1=\mathrm{AC}\left(\mathrm{C}_{\mathrm{H} 1 \mathrm{q}}, \mathrm{C}_{\mathrm{V} 1 \mathrm{q}}, \mathrm{C}_{\mathrm{D} 1 \mathrm{q}}\right) \text {; }
$$

$$
\mathrm{R} 2=\mathrm{HC}\left(\mathrm{C}_{\mathrm{H} 2 \mathrm{q}}, \mathrm{C}_{\mathrm{V} 2 \mathrm{q}}, \mathrm{C}_{\mathrm{D} 2 \mathrm{q}}\right) \text {; }
$$

Step 5. 2D-DCT technique is applied to the $\mathrm{C}_{\mathrm{A} 2}$ sub-band.

$$
\mathrm{DCT}\left(\mathrm{C}_{\mathrm{A} 2}\right. \text { sub-band); }
$$

Step 6. The output of step 5 is the compressed image.

For decompression, the steps are as given below:

Step 1. 2D-IDCT technique is applied on the LL3 sub-band. Inverse_DCT $\left(\mathrm{C}_{\mathrm{A} 2}\right.$ sub-band $)$;

Step 2. Arithmetic \& Huffman decoding is applied on sub-bands of $2^{\text {nd }}$ level (HL2, HL2, and HH2) \& $3^{\text {rd }}$ level (HL3, HL3, and HH3) corresponding compressed bands.

For arithmetic decoding:

For Huffman decoding:

$$
\mathrm{R}_{1}=\mathrm{AC}\left(\mathrm{C}_{\mathrm{H} 1 \mathrm{q}}, \mathrm{C}_{\mathrm{V} 1 \mathrm{q}}, \mathrm{C}_{\mathrm{Dlq}}\right)
$$

$$
\mathrm{R}_{2}=\mathrm{HC}\left(\mathrm{C}_{\mathrm{H} 2 \mathrm{q}}, \mathrm{C}_{\mathrm{V} 2 \mathrm{q}}, \mathrm{C}_{\mathrm{D} 2 \mathrm{q}}\right)
$$

Step 3. IDWT is applied on extracted RGB up to the third level.

For first-level inverse DWT:

$\left[\mathrm{C}_{\mathrm{A}}, \mathrm{C}_{\mathrm{H}}, \mathrm{C}_{\mathrm{V}}, \mathrm{C}_{\mathrm{D}}\right]=$ Inverse_DWT( $\mathrm{R}_{1}$, 'filter_name');

For second-level inverse DWT:

$\left[\mathrm{C}_{\mathrm{A} 1}, \mathrm{C}_{\mathrm{H} 1}, \mathrm{C}_{\mathrm{V} 1}, \mathrm{C}_{\mathrm{D} 1}\right]=$ Inverse_DWT $\left(\mathrm{C}_{\mathrm{A}}\right.$, 'filter_name' $)$;

For third-level inverse DWT:

$\left[\mathrm{C}_{\mathrm{A} 2}, \mathrm{C}_{\mathrm{H} 2}, \mathrm{C}_{\mathrm{V} 2}, \mathrm{C}_{\mathrm{D} 2}\right]=$ Inverse_DWT( $\mathrm{C}_{\mathrm{A} 1}$, 'filter_name' $)$;

Step 4. Decoded image $=\operatorname{cat}(3$, components $)$;

\section{A. Performance Matrices}

For a good quality image after decompression, PSNR should be high. PSNR is defined as [22- 25]:

$$
\text { PSNR }=\log 10\left(\frac{\mathrm{MAx}_{\mathrm{i}}^{2}}{\mathrm{MSE}}\right)
$$

Where $\mathrm{MAX}_{\mathrm{i}}^{2}$ is the maximum pixel intensity values. And MSE is the Mean square error among original and decompressed image and is defined as:

$$
\operatorname{MSE}=\frac{1}{\mathrm{MN}} \sum_{\mathrm{i}=0}^{\mathrm{M}-1} \sum_{\mathrm{j}=1}^{\mathrm{N}-1}\left[\{\mathrm{x}(\mathrm{i}, \mathrm{j})-\mathrm{y}(\mathrm{i}, \mathrm{j})\}^{2}\right]
$$

CR formula is defined as [22-23]: CR is a parameter by which measure the how many times image compressed.

$$
\mathrm{CR}=\frac{\text { Size of the original image }}{\text { Size of Compressed image }}
$$




\section{Simulation results}

\subsection{Result of Arithmetic and Huffman Coding \& DWT-DCT Technique on Lena's Images}

The original colored image of Lena is extracted into its three components, i.e., red, green, and blue as shown in Fig. 2. Each of the components is compressed using Arithmetic \& Huffman coding and DCT-DWT based hybrid technique. Figs. 3 and 4 show the decoded Lena image for arithmetic and Huffman coding with .jpg and .bmp file extensions, respectively. From Figs. 3 and 4 it is clear that the blocking effect is eliminated in the decoded images (green and blue components) and more effective.

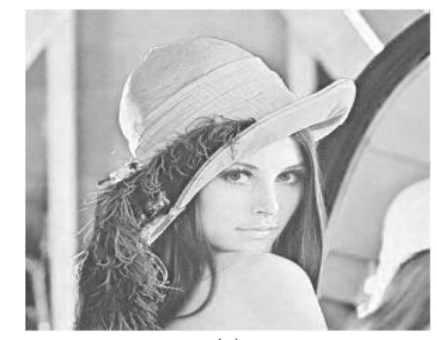

(a)

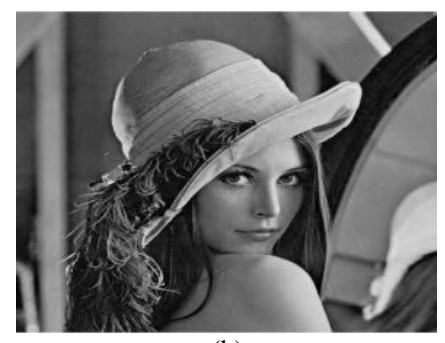

(b)

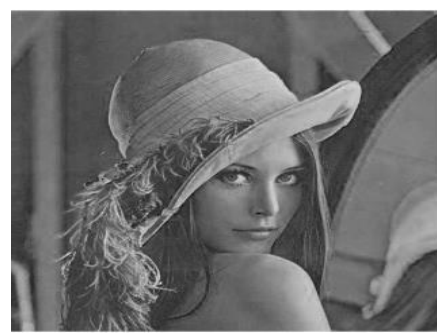

(c)

Fig. 2. Extracted Lena image (a) Red (b) Green (c) Blue

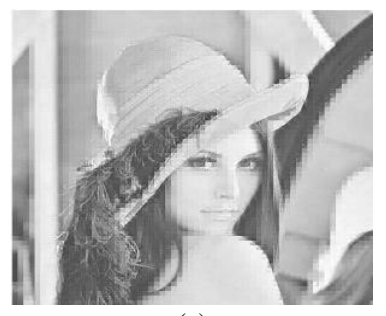

(a)

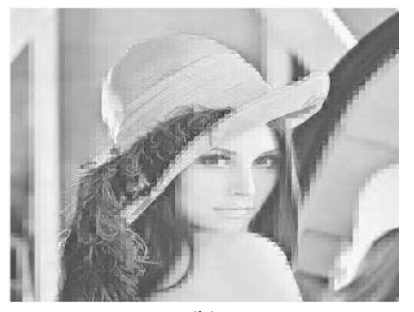

(b)

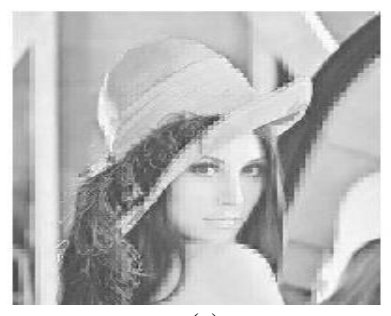

(c)

Fig. 3. Decoded Lena image using Arithmetic coding (a) Red (b) Green (c) Blue

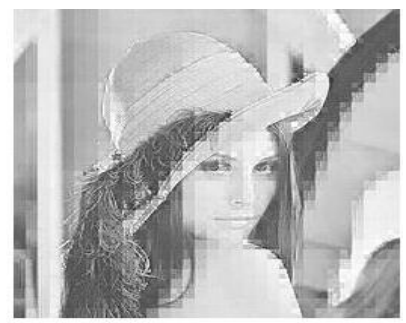

(a)

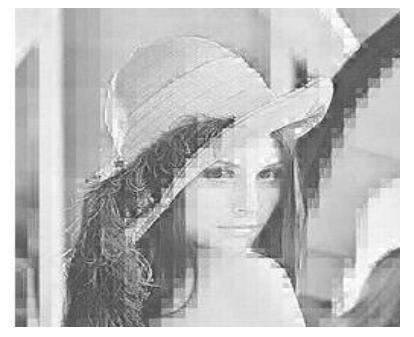

(b)

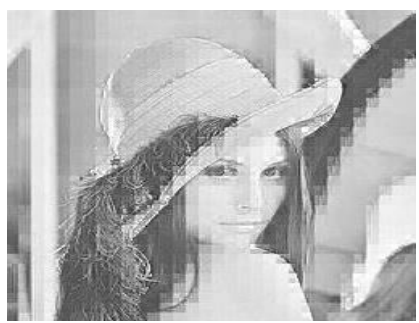

(c)

Fig. 4. Decoded Lena image using Huffman coding (a) Red (b) Green (c) Blue

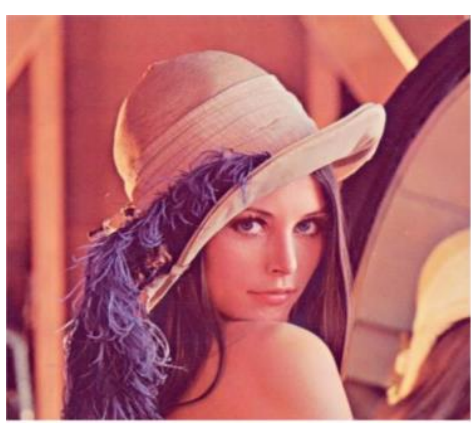

(a)

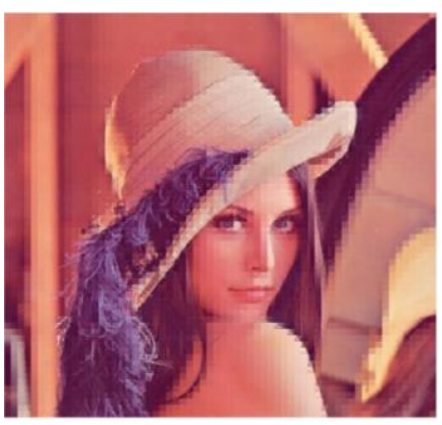

(b)

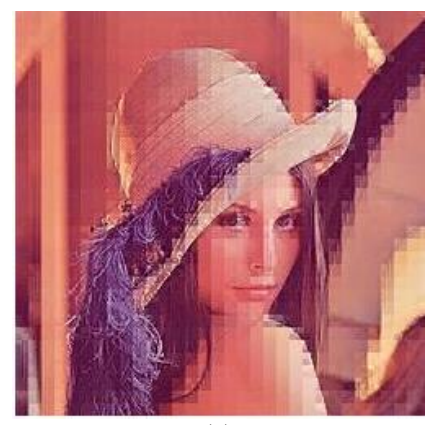

(c)

Fig. 5. (a) Original Lena color image (b) Decoded image using Arithmetic coding (c) Decoded image using Huffman coding 
Fig. 5 compares the original Lena image with the decoded images using Arithmetic and Huffman coding techniques. Table 1 represents the comparison between filters for RGB color images (.jpg and .bmp) by using Arithmetic and Huffman coding.

Table 1. Result of Arithmetic and Huffman based on DWT-DCT technique (Lena image)

\begin{tabular}{|c|c|c|c|c|c|c|c|c|}
\hline \multirow{2}{*}{$\begin{array}{l}\text { Image name } \\
\text { and extension }\end{array}$} & \multirow{2}{*}{ Filter } & \multirow{2}{*}{$\begin{array}{l}\text { Colour } \\
\text { image }\end{array}$} & \multicolumn{3}{|c|}{$\begin{array}{c}\text { Based on the Arithmetic and DWT-DCT } \\
\text { technique }\end{array}$} & \multicolumn{3}{|c|}{$\begin{array}{c}\text { Based on Huffman and DWT-DCT } \\
\text { technique }\end{array}$} \\
\hline & & & MSE & $\operatorname{PSNR}(\mathrm{dB})$ & CR & MSE & PSNR(dB) & CR \\
\hline \multirow{2}{*}{ Lena (.jpg) } & db9 & RGB & 159.8641 & 25.1873 & 2.0014 & 73.2984 & 28.4798 & 2.0018 \\
\hline & haar & RGB & 109.3705 & 26.3412 & 2.0001 & 191.2389 & 24.5152 & 2.0006 \\
\hline \multirow{2}{*}{ Lena (.bmp) } & db9 & RGB & 158.7496 & 25.0231 & 2.0011 & 161.2452 & 25.1553 & 2.0011 \\
\hline & haar & RGB & 109.3464 & 26.4422 & 2.0004 & 199.0584 & 24.3415 & 2.0005 \\
\hline
\end{tabular}

Table 1 shows the compression result for Lena image using Arithmetic coding and Huffman coding based on DWT and DCT methods. In this table, we have evaluated the values of the RGB Lena image using two different filters with two different extensions. The Lena (.jpg) image using the haar filter gives a high PSNR (26.4422) value and the Lena (.jpg) image using the db9 filter gives a high CR (2.0014). The Lena (.bmp) image using the db9 filter gives a low PSNR (25.0231) value and the Lena (.jpg) image using haar filter gives low CR (2.0001). For Huffman coding, the Lena (.jpg) image using db9 gives a high PSNR (28.4798) value and the Lena (.jpg) image using db9 gives a high CR (2.0018). The Lena (.bmp) image using the haar filter gives a low PSNR (24.3415) value and the Lena (.bmp) image using the db9 filter gives low CR (2.005).

\subsection{Result of Arithmetic-Huffman Coding and DCT Technique on Lena's Images}

The original image of Baboon is extracted into its three components, i.e., red, green, and blue as shown in Fig. 6. Fig. 6 and 7 show the decoded baboon image using arithmetic coding in .jpg and .bmp format, respectively. Fig. 8 and 9 show the decoded baboon image using Huffman coding in .jpg and .bmp format, respectively. After compression, each of the components is compressed using Arithmetic \& Huffman coding and DCT-DWT based hybrid technique. From Figs. 6, 7, 8, and 9, it is clear that the green and blue parts of the image are more affected due to the reason of removing using DCT of the blocking effects.

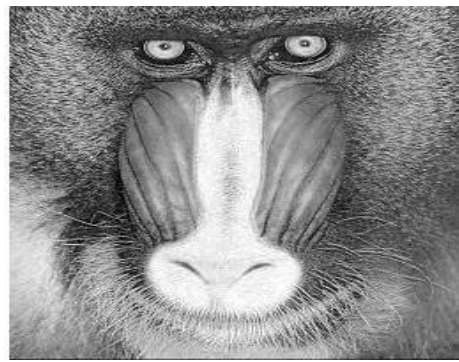

(a)

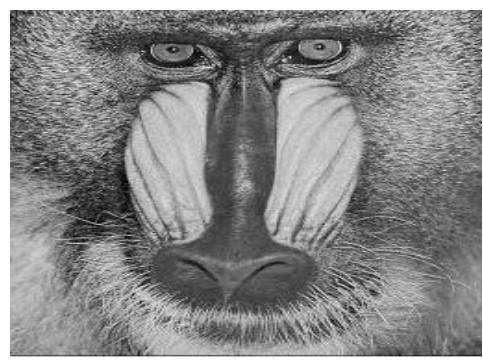

(b)

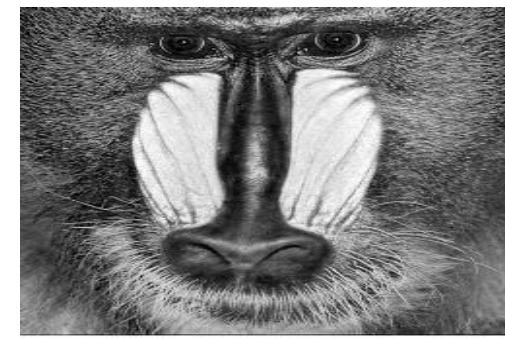

(c)

Fig. 6. Decoded Baboon image using Arithmetic coding (a) Red (b) Green (c) Blue

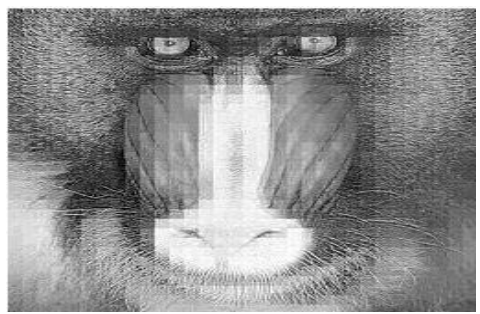

(a)

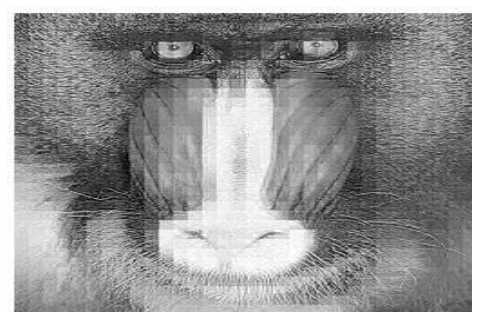

(b)

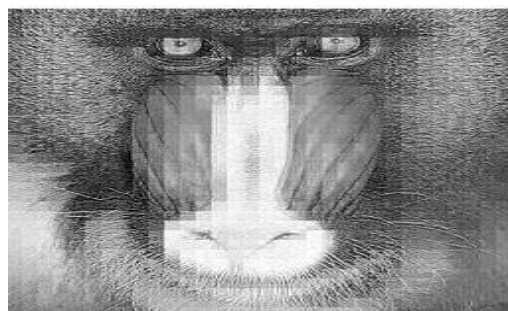

(c)

Fig. 7. Decoded Baboon image using Arithmetic coding (a) Red (b) Green (c) Blue 


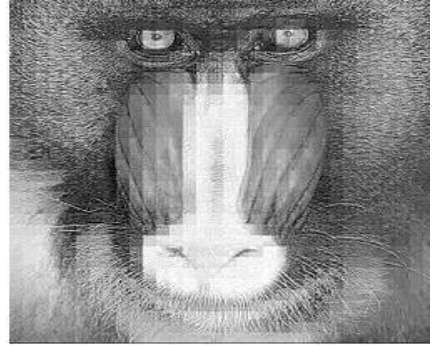

(a)

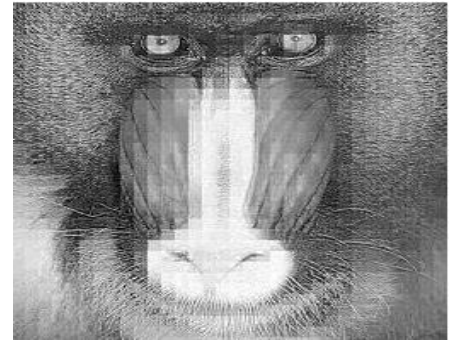

(b)

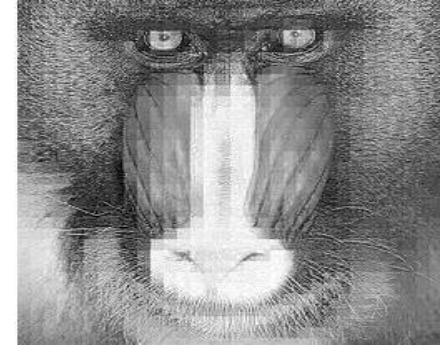

(c)

Fig. 8. Decoded Baboon image using Huffman coding (a) Red (b) Green (c) Blue

Fig. 9 shows the comparison between the original colored image of Baboon with the decoded images using Arithmetic and Huffman coding techniques.

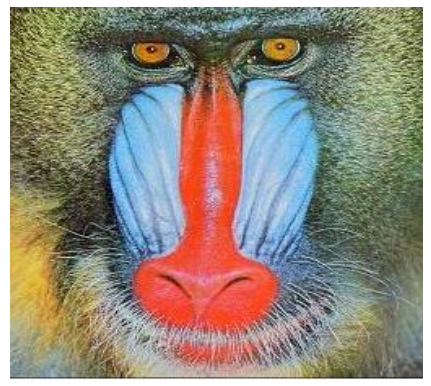

(a)

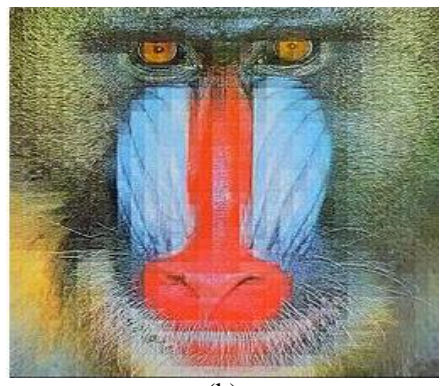

(b)

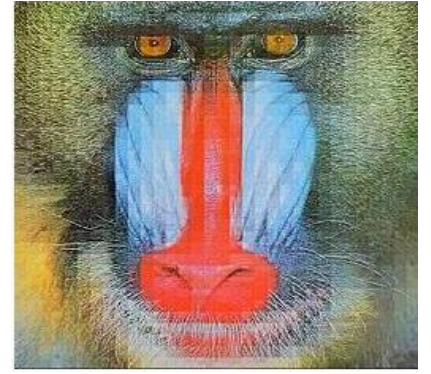

(c)

Fig. 9. (a) Original Baboon color image (b) Decoded image using Arithmetic coding (c) Decoded image using Huffman coding

Table 2. Result of Arithmetic and Huffman and DWT-DCT Technique (Baboon image)

\begin{tabular}{|c|c|c|c|c|c|c|c|c|}
\hline \multirow{2}{*}{$\begin{array}{l}\text { Image name } \\
\text { and extension }\end{array}$} & \multirow{2}{*}{ Filter } & \multirow[t]{2}{*}{ Colour image } & \multicolumn{3}{|c|}{$\begin{array}{c}\text { Based on the Arithmetic and DWT-DCT } \\
\text { technique }\end{array}$} & \multicolumn{3}{|c|}{$\begin{array}{c}\text { Based on Huffman and DWT-DCT } \\
\text { technique }\end{array}$} \\
\hline & & & MSE & $\operatorname{PSNR}(\mathrm{dB})$ & CR & MSE & $\operatorname{PSNR}(\mathrm{dB})$ & CR \\
\hline \multirow{2}{*}{$\begin{array}{l}\text { Baboon } \\
\text { (.jpg) }\end{array}$} & db9 & RGB & 211.9374 & 23.4564 & 1.9180 & 5898.4554 & 10.4234 & 2.0006 \\
\hline & haar & RGB & 238.8621 & 24.3493 & 2.1218 & 5869.4571 & 10.4448 & 2.0006 \\
\hline \multirow{2}{*}{$\begin{array}{l}\text { Baboon } \\
\text { (.bmp) }\end{array}$} & db9 & RGB & 211.9844 & 24.8678 & 2.0108 & 5897.9344 & 10.4238 & 2.0005 \\
\hline & haar & RGB & 238.8681 & 24.3492 & 2.3428 & 5869.4571 & 10.4448 & 2.0006 \\
\hline
\end{tabular}

Table 2 represents the comparison between filters for RGB color images (.jpg and .bmp) by using arithmetic and Huffman coding. Table 2 shows the compression results of RGB color images after compression using the arithmetic coding and Huffman coding based on DWT and DCT methods. This table evaluated the values based on two filters for two images of two different extensions. The Baboon (.jpg) image using the db9 filter, gives a high PSNR value. The Baboon (.bmp) image using a haar filter gives high CR values and using the haar filter gives a low PSNR value. The Baboon (.jpg) image using the db9 filter gives low CR. For Huffman coding, the Baboon (.jpg) image using the db9 filter gives high PSNR values and the Baboon (.bmp) image using haar filter gives high CR. The Baboon (.bmp) using db9 filter gives low PSNR and the baboon (.jpg) using haar filter gives low CR.

\section{Conclusion and Future Work}

In this paper, a hybrid image compression scheme based on the DWT-DCT using Arithmetic and Huffman coding has been discussed. These schemes use the features of DWT and DCT transformation schemes to achieve the compression requirements. The simulation result gives a good combination of PSNR and CR for standard images using MATLAB. DWT-DCT schemes produced higher PSNR and CR values using encoding and decoding methods. In this paper, we have evaluated the PSNR and CR values for standard color images. DWT-DCT based image compression schemes such as arithmetic coding perform a very high compression ratio by using haar filter and for Huffman coding 
by using db9 filter. The simulation result of this paper is acceptable because the lossless technique of CR is varying from 2 to 8 [26]. As future work, these methods can be implemented for video files.

\section{References}

[1] Sayood, K. (2006). Introduction to Data Compression. San Francisco: Morgan Kaufmann.

[2] Gonzalez, R. C., \& Woods, R. E. (2002). Digital Image Processing. New Jersey: Pearson Prentice Hall.

[3] Dorairangaswamy, M. A \&Padhmavathi, B. (2009). An effective blind watermarking scheme for protecting rightful ownership of digital images. In TENCON 2009 IEEE Region 10 Conference, 1-6.

[4] Wu, M. S. (2014). Genetic algorithm based on discrete wavelet transformation for fractal image compression. Journal of Visual Communication and Image Representation, 25(8), 1835-1841.

[5] Corinthios, Benchikh, S \& Michael. (2011). A Hybrid Image Compression Technique Based On DWT and DCT Transforms, 1049-1065. Canada: IEEE.

[6] Mohammed, A. A \& Hussein, J. A. (2010). Hybrid transform coding scheme for medical image application. 2010 IEEE International Symposium on Signal Processing and Information Technology (ISSPIT), 237-240.

[7] Chang, C. C., Lin, C. C., Tseng, C. S \& Tai, W. L. (2007). Reversible hiding in DCT-based compressed images. Information Sciences, 177(13): 2768-2786.

[8] Yuen, C. H., \& Wong, K. W. (2011). A chaos-based joint image compression and encryption scheme using DCT and SHA1. Applied Soft Computing, 11(8), 5092-5098.

[9] Gershikov, E., Lavi-Burlak, E \&Porat, M. (2007). Correlation-based approach to color image compression. Signal Processing: Image Communication, 22(9): 719-733.

[10] Wu, J., Xu, Z., Jeon, G., Zhang, X., \& Jiao, L. (2013). Arithmetic coding for image compression with adaptive weight-context classification. Signal Processing: Image Communication, 28(7), 727-735.

[11] Marpe, D., Schwarz, H \& Wiegand, T. (2003). Context-based adaptive binary arithmetic coding in the H. 264/AVC video compression standard. Circuits and Systems for Video Technology, IEEE Transactions on, 13(7): 620-636.

[12] Das, S., \& Rao, P. N. (2012). Arithmetic coding based lossless compression schemes for power system steady state operational data. International Journal of Electrical Power \& Energy Systems, 43(1), 47-53.

[13] Lin, Q., Wong, K. W., \& Chen, J. (2013). An enhanced variable-length arithmetic coding and encryption scheme using chaotic maps. Journal of Systems and Software, 86(5), 1384-1389.

[14] Vijayabhaskar, P. V. M \&Raajan, N. R. (2013). Comparison of wavelet filters in image coding using hybrid compression technique.2013 International Conference on Emerging Trends in VLSI, Embedded System, Nano Electronics and Telecommunication System (ICEVENT), 1-5.

[15] Elabdalla, A. R., \&Irshid, M. I. (2001). An efficient bitwise Huffman coding technique based on source mapping. Computers \& Electrical Engineering, 27(3), 265-272.

[16] Zolghadr-E-Asli, A., \&Alipour, S. (2004). An effective method for still image compression/decompression for transmission on PSTN lines based on modifications of Huffman coding. Computers \& Electrical Engineering, 30(2), 129-145.

[17] Abouali, A. H. (2015). Object-based VQ for image compression. Ain Shams Engineering Journal, 6(1), 211-216.

[18] Yang, C. K., \& Tsai, W. H. (1998). Color image compression using quantization, thresholding, and edge detection techniques all based on the moment-preserving principle. Pattern Recognition Letters, 19(2), 205-215.

[19] Xiong, Z., Ramchandran, K., \& Orchard, M. T. (2002). Space-frequency quantization for wavelet image coding. In Wavelet Image and Video Compression (pp. 171-197). Springer US.

[20] Chen, Y. Y. (2007). Medical image compression using DCT-based subband decomposition and modified SPIHT data organization. International journal of medical informatics, 76(10): 717-725.

[21] Starosolski, R. (2014). New simple and efficient color space transformations for lossless image compression. Journal of Visual Communication and Image Representation, 25(5): 1056-1063.

[22] ZainEldin, H., Elhosseini, M. A., \& Ali, H. A. (2014). Image compression algorithms in wireless multimedia sensor networks: A survey. Ain Shams Engineering Journal.

[23] Zhu, H., Zhao, C., \& Zhang, X. (2013). A novel image encryption-compression scheme using hyper-chaos and Chinese remainder theorem. Signal Processing: Image Communication, 28(6), 670-680.

[24] Zhu, J. Y., Wang, Z. Y., Zhong, R., \& Qu, S. M. (2015). Dictionary based surveillance image compression. Journal of Visual Communication and Image Representation, 31, 225-230.

[25] Hussain, A. J., Al-Jumeily, D., Radi, N., \&Lisboa, P. (2015). Hybrid Neural Network Predictive-Wavelet Image Compression System. Neurocomputing, 151, 975-984.

[26] Al-Bahadili, H. (2008). A novel lossless data compression scheme based on the error correcting Hamming codes. Computers \& Mathematics with Applications, 56(1), 143-150.

[27] Kumar, R., \& Yadav, J. (2020). A Robust Speech Watermarking Techniques using Arnold Transform based on multidimensional multilevel DWT method. Test Engineering \\& management, Vol. 83, (pp. 22661- 22671).

[28] Kumar, M., Kumar, R., \& Yadav, J. (2020). A Robust Digital Speech Watermarking Based on Least Significant Bit. International Journal of Innovative Technology and Exploring Engineering (IJITEE), 9(6), (pp. 126-131).

[29] Kumar, R., Kumar, Brar, S. S. (2016, December). Video quality evaluation using DWT-SPIHT based watermarking technique. In 2016 11th International Conference on Industrial and Information Systems (ICIIS) (pp. 1-6). IEEE.

[30] Kumar, G., Brar, E. S. S., Kumar, R., and Kumar, A. (2015). A review: DWT-DCT technique and arithmetic-Huffman coding based image compression. International Journal of Engineering and Manufacturing, 5(3), 20. 


\section{Authors' Profiles}

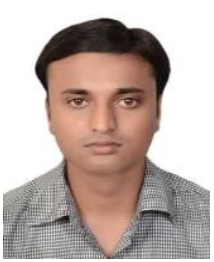

Gaurav Kumar received the B. Tech degree in Information Technology from Guru Gobind Singh Indraprastha University, Delhi in the year 2012 and the M. Tech degree in Computer Science \& Technology from Central University of Punjab, Bathinda in 2015. He has qualified GATE examination. Currently working as Block IT Assistant in Govt. of Bihar (India). His research area interest is in the area of image and video compression.

Publication: Kumar, G., Brar, E. S. S., Kumar, R., and Kumar, A. (2015). A review: DWT-DCT technique and arithmetic-Huffman coding based image compression. International Journal of Engineering and Manufacturing, 5(3), 20.

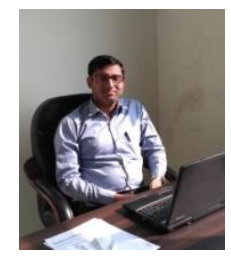

Rajeev Kumar is pursuing a Ph.D. from the central university of south Bihar. He has completed a B.Tech degree from Gandhi Institute for Technological Advancement, Bhubaneswar. He has completed an M.Tech degree from Central University of Punjab, Bathinda, 2015. He has qualified for CBSE-NET and GATE examinations. His research area interest is in the field of signal processing, image compression, video watermarking, and Speech watermarking. He has published and presented papers in different journals and conferences.

How to cite this paper: Gaurav Kumar, Rajeev Kumar, " Analysis of Arithmetic and Huffman Compression Techniques by Using DWT-DCT", International Journal of Image, Graphics and Signal Processing(IJIGSP), Vol.13, No.4, pp. 63-70, 2021.DOI: 10.5815/ijigsp.2021.04.05 